\title{
Analysis and Clinical Importance of Superficial Arterial Palmar Irrigation and its Variants over 86 Cases
}

\author{
Análisis e Importancia Clínica de la Irrigación Arterial \\ Palmar Superficial y sus Variaciones sobre 86 Casos
}

\author{
Nicolás Ernesto Ottone; Natalia Prum; Mario Dominguez; Esteban Blasi; \\ Carlos Medan; Sergio Shinzato; Diana Finkelstein \& Vicente Hugo Bertone
}

OTTONE, N. E.; PRUM, N.; DOMINGUEZ, M.; BLASI, E.; MEDAN, C.; SHINZATO, S.; FINKELSTEIN, D.; BERTONE, V. H. Analysis and clinical importance of superficial arterial palmar irrigation and its variants over 86 cases. Int. J. Morphol., 28(1):157$164,2010$.

SUMMARY: The classic description of the hand's superficial palmar arch is based on the anastomosis among the ulnar and radiopalmar arteries, a branch of the radial artery. However, the arch formation is highly variable regarding the size of the arteries that make it up and due to the existence of branches coming from other arteries and adding up as tributary to it. The objective of this paper is to classify these possible varieties, to define the formation of the arch, the reasons for its variable arrangement and the importance of its clinical and surgical applications. 86 formalized hands were dissected at $40 \%$. There is prevalence concerning the size of the ulnar artery, with or without an arch. The anatomic knowledge of the variability in the arch formation becomes important in the application of surgical techniques that can help treating pathologies of the hand.

KEY WORDS: Superficial palmar arch; Anatomy; Anatomical variations; Hand.

\section{INTRODUCTION}

The radial and ulnar arteries, together with other vessels, form the superficial and deep palmar arterial arches. According to the classic description (Bouchet \& Cuilleret, 1997; Casiraghi et al., 1969; Goss, 1976; Little et al., 1973; Testut \& Latarjet, 1954), anastomosis among the ulnar and radiopalmar arteries gives rise to the superficial palmar arch, from which the palmar digital arteries derive.

Nonetheless, the formation that is considered "normal" is highly variable. Kaplan (1961) believe that in 66\% of cases, the superficial palmar arch is formed by the ulnar artery. The most common disposition is the ulnar artery ending in the second metacarpal space and the thumb's two collateral palmars and the index's collateral radial being supplied by the radial artery.

Furthermore, Adachi (1928) thinks that the superficial palmar arch has an ulnar-prevalent formation, which he calls the Ulnar-type and finds it in $59 \%$ of cases.
On the other hand, unlike the two cited authors, Coleman \& Anson (1961) developed a classification in which the superficial palmar arch is formed in $78.46 \%$ of cases, and consider this described arrangement as "classic" in $34.5 \%$.

Therefore, the objective of this paper is to analyze the actual formation of the superficial palmar arch, defining the reasons for its variable arrangement, the importance of its knowledge and its clinical and surgical applications.

\section{MATERIAL AND METHOD}

A total number of 86 hands, 46 left ones and 40 right ones, were dissected and formolized at $10 \%$ with no sex or age discrimination. Because of variability it was no possible to establish statistical significant differences. The dissection 
technique was based on the search for the superficial palmar arch respecting the different planes present from the surface to the deep part. Regular surgical instruments were use.

\section{RESULTS}

As seen in Figure 1, we have grouped the results on the basis of the following classification:

Type: it indicates the presence or absence of a properly shaped vascular arch.

Subtype: a subdivision of the Type arrangement indicating which the tributary arteries of the superficial palmar system are.
Pattern: it determines the prevalence of the tributary arteries of the superficial palmar system.

According to our investigation, over a total amount of 86 dissected hands, we have observed a first major division into two types: Arch Type and Non Arch Type.

The existing Arch Type responds to the existence of an arterial system formed by the union of two arteries and whose arrangement involves the geometric pattern we commonly call "arch" in the strict sense. In turn, the palmar digitals that are later divided into the fingers collaterals originate in this arch. This arrangement was found in 50 cases $(58.0 \%)$.

In the Non Arch Type there is no proper vascular "arch" formation. The area vascularized by the arch is replaced by one artery (alone) or two (mutually independent)

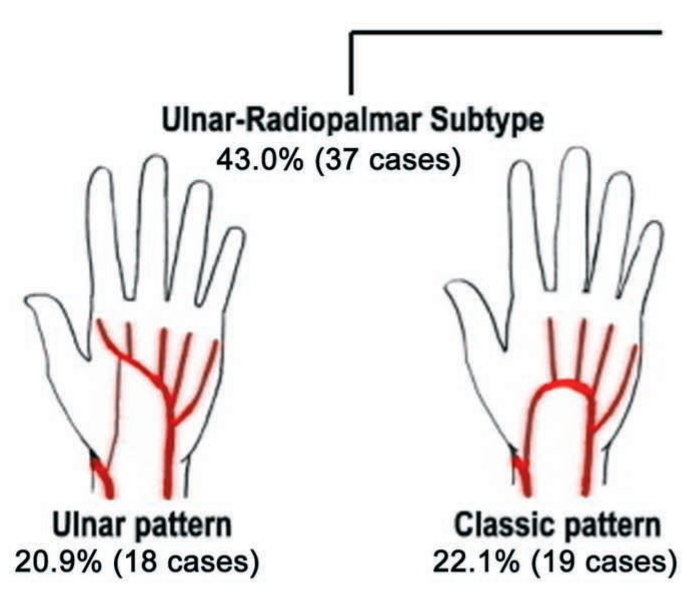

\section{Arch Type $58.0 \%$ (50 cases)}
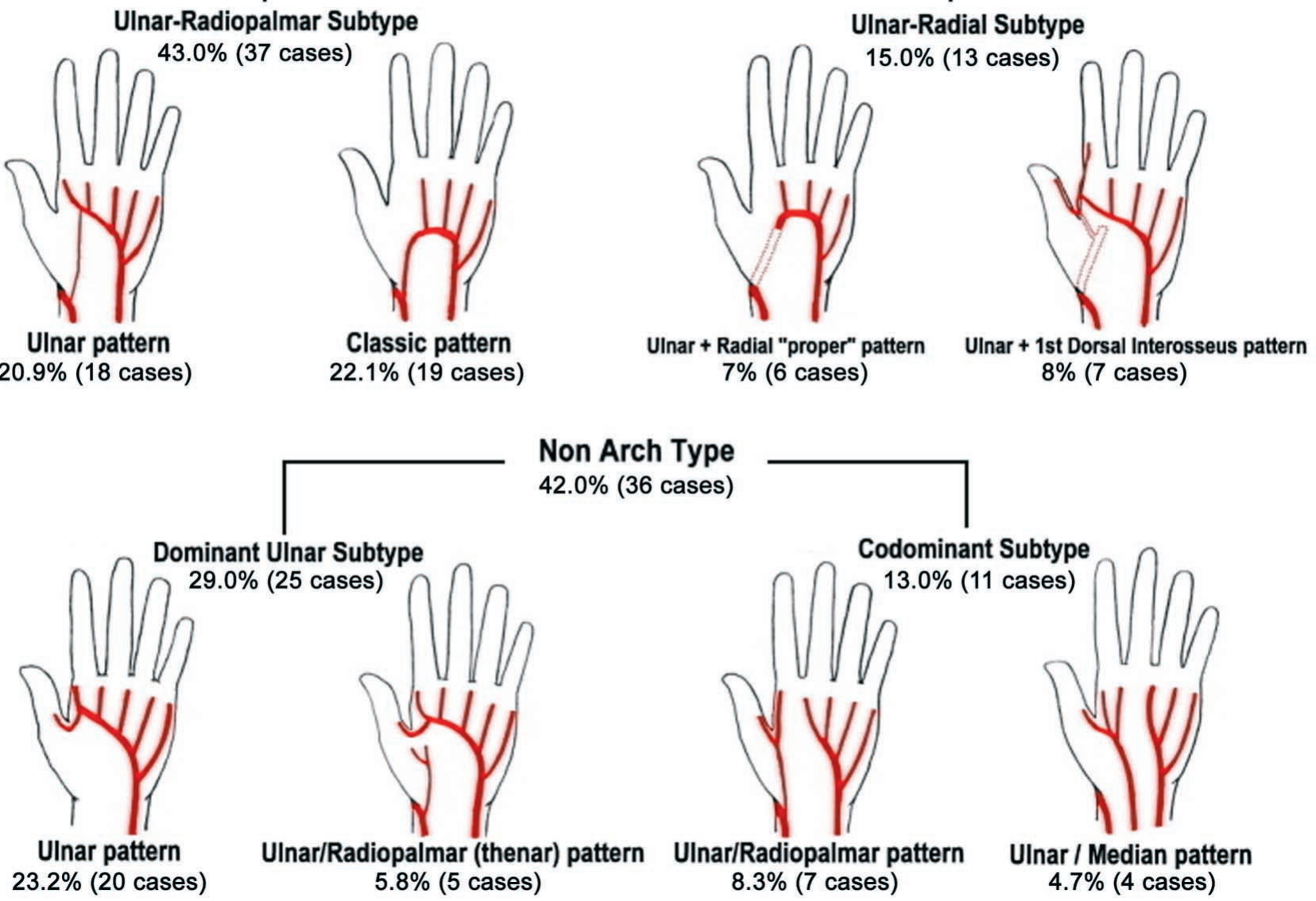

$7 \%$ (6 cases)

$8 \%$ ( 7 cases)

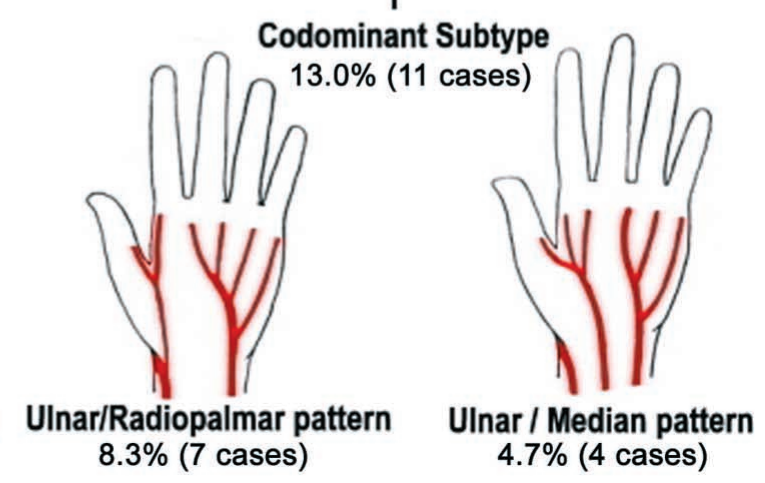

Fig. 1. Classification of the superficial arterial palmar irrigation. 


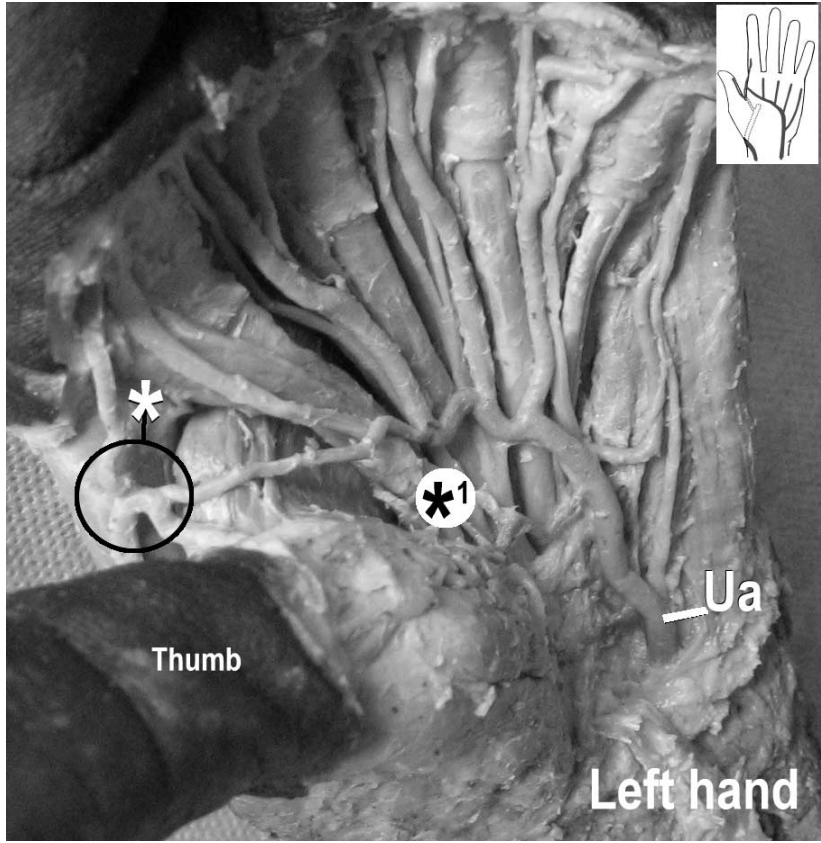

Fig. 2a. Ulnar + 1st Dorsal Interosseus pattern. Ua. Ulnar artery; * "crossroads" style; *1 absence of radiopalmar artery.

arteries. Whatever the found subtype might be, they are in charge of supplying the whole superficial vascularization for the palm of the hand. This arrangement was found in the 36 remaining cases $(42.0 \%)$ out of the 86 dissectedhands.

Within the existing Arch Type, there are two subtypes.

Ulnar-Radiopalmar Subtype (37 cases; 43.0\%): the proper arch exists and is formed by the union between the ulnar and radiopalmar arteries, a branch of the radial artery. This subtype can be divided in two ways:

-Ulnar Pattern (18 cases; 20.9\%): the particular characteristic of this arrangement is that the ulnar artery has a larger size than the radiopalmar artery (approximately double its size) and, as a result, all the palmar digital arteries are supplied by the part of the arch formed by the ulnar artery. The radiopalmar artery would participate in the "arch" formation only in its closure and by supplying some branch of minor importance at the level of the thenar muscles.

- Classic Pattern (19 cases; 22.1\%) (Figure 4): it refers to the arrangement described by ancient anatomists (Goss, 1976; Testut \& Latarjet) who believed that the superficial palmar arch is normally formed by anastomosis among the ulnar and radiopalmar arteries, both of the same size.

Ulnar-Radial Subtype (13 cases; $15.0 \%$ ): Based on the participating arteries, the arch has an antero-posterior

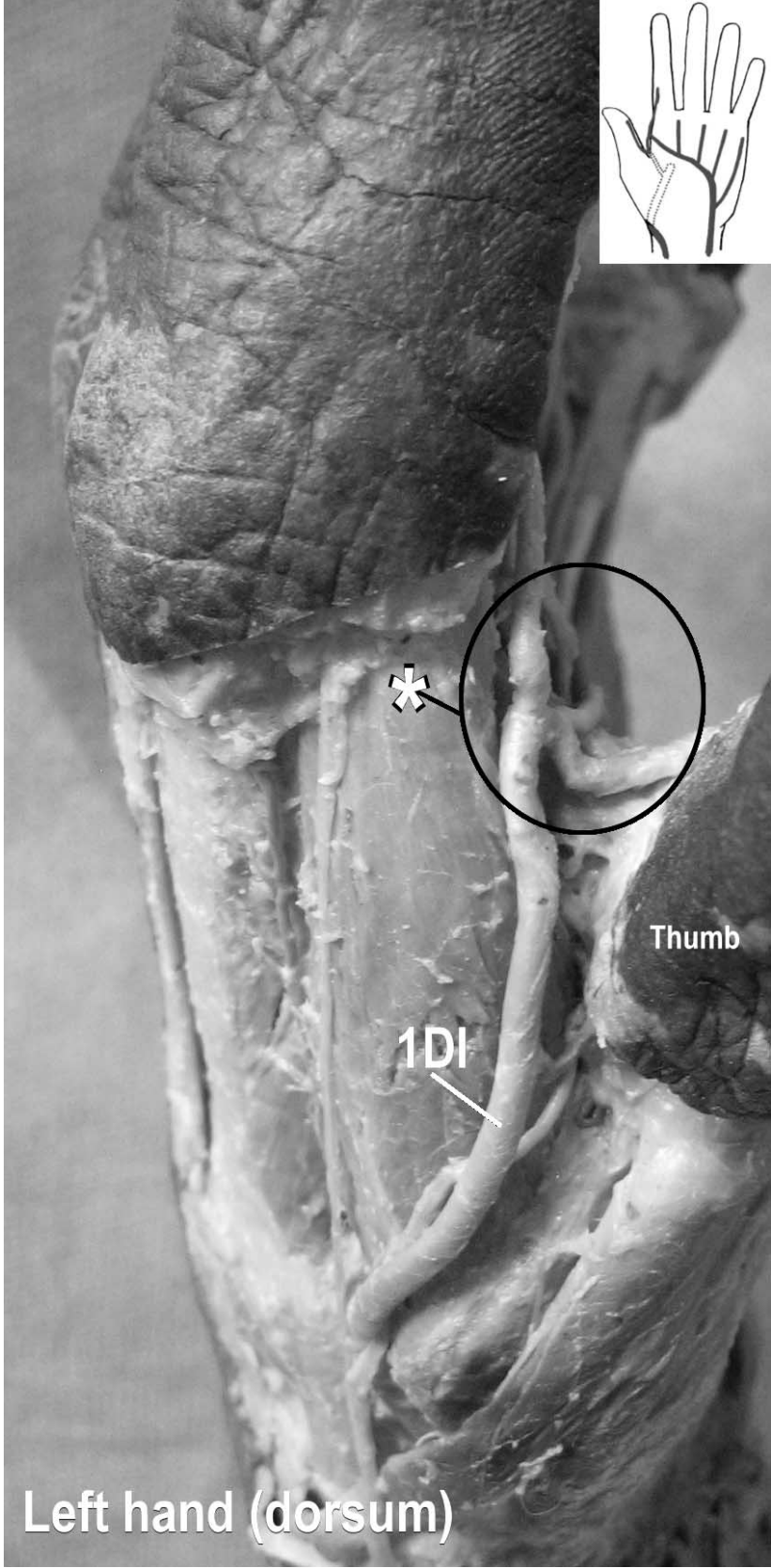

Fig. 2b. Ulnar +1 st Dorsal Interosseus pattern. 1DI. 1st Dorsal Interosseus artery; * "crossroads" style.

(palmar to dorsal) arrangement. Depending on the artery anastomosing with the ulnar (always present) artery, this subtype can be as follows:

- Ulnar + Radial "Proper" Pattern (6 cases; 7.0\%): the radial artery, once it leaves its dorsal pathway, reaches the deep palmar region when going through the upper side of the first interosseal space anastomosing at this level with the ulnar artery. 


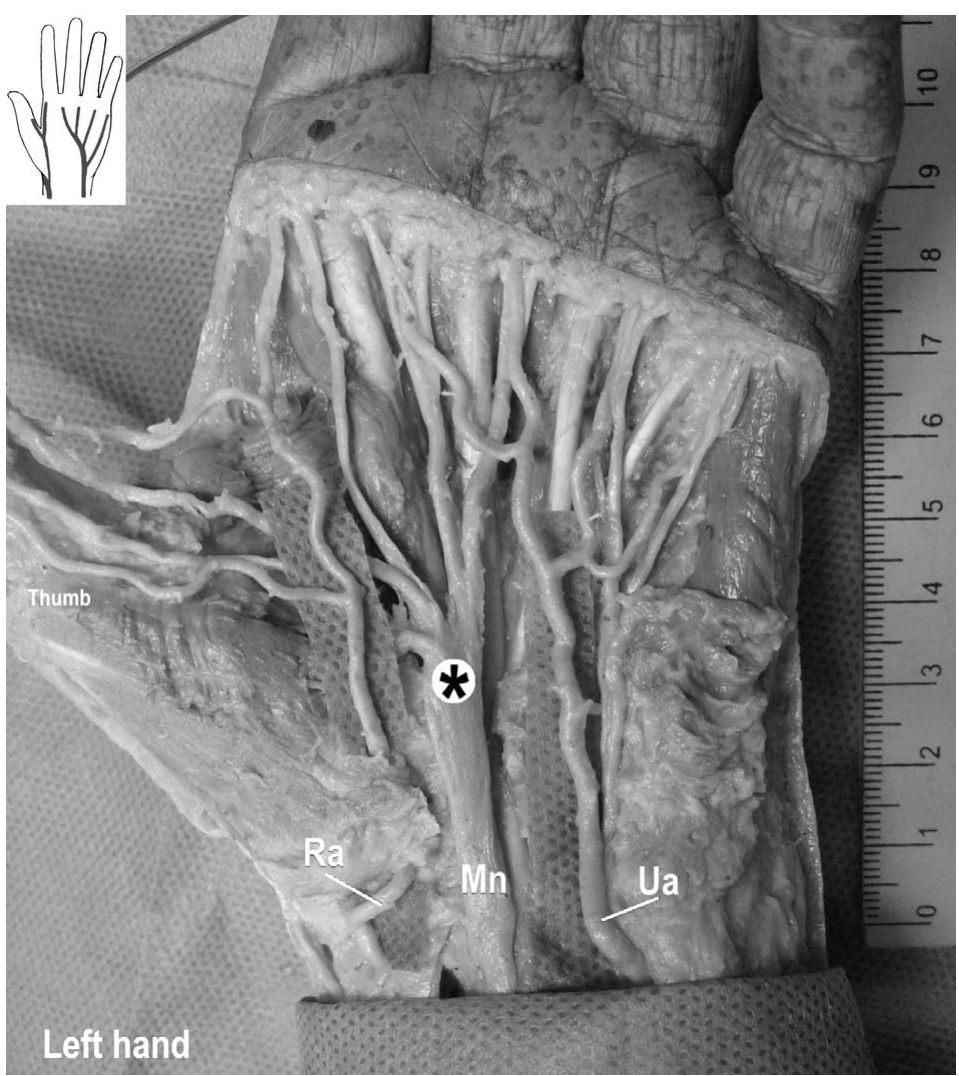

Fig. 3. Ulnar / Radiopalmar pattern. RPa, Radiopalmar artery; Ua. Ulnar artery; Mn., Median nerve; * absence of anastomosis between radiopalmar and ulnar arteries.

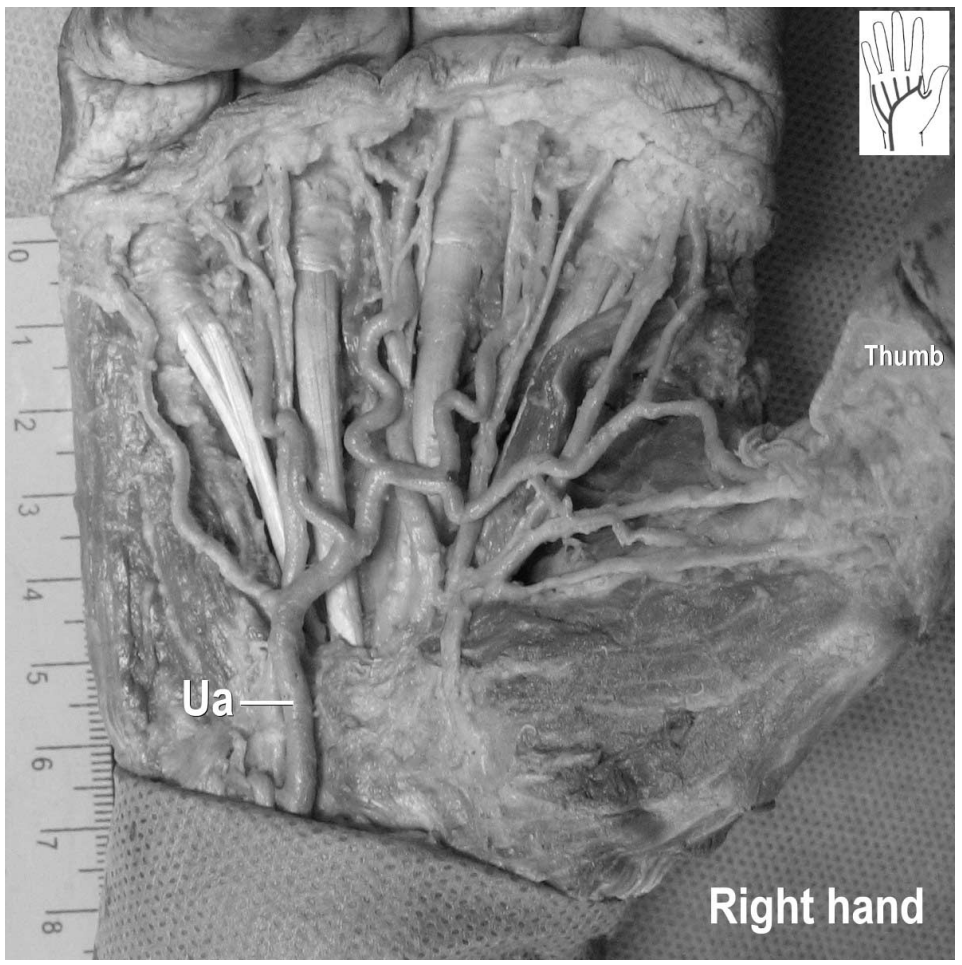

Fig. 4. Ulnar pattern. Ua. Ulnar artery.
- Ulnar + 1st Dorsal Interosseal Artery Pattern (7 cases; 8.0\%) (Figs. 2a and 2b): anastomosis, allowing for the arch formation, happens between the ulnar and 1st dorsal interosseal arteries, with the ulnar artery going a long way which includes passing through the first commissure. In turn, the 1st dorsal interosseal artery always has a big size, replacing the thumb dorsal.

Regarding the Non Arch Type, there are two subtypes:

Dominant Ulnar Subtype (36 cases; 42.0\%): in this arrangement, the ulnar artery is the only artery responsible for the formation of the superficial palmar arterial system; thus, it is the only one in charge of supplying the palmar digital arteries. This subtype has two forms:

- Ulnar Pattern (20 cases; 23.2\%): the ulnar artery is completely in charge of the superficial palmar vascularization in the absence of a radiopalmar artery.

- Ulnar/Radiopalmar (Thenar) Pattern (5 cases; $5.8 \%$ ): as in the ulnar pattern, this artery supplies the whole of the superficial palmar irrigation, but in the presence of a small radiopalmar artery ending at the level of the thenar muscles.

Codominant Subtype (11 cases; 13.0\%): this subtype refers to the presence of two arteries, which irrigate two totally independent areas. There are two patterns:

- Ulnar/Radiopalmar Pattern (7 cases; 8.3\%) (Fig. 3).

Ulnar/Median Artery Pattern (4 cases; 4.7\%) (Fig. 6).

\section{DISCUSSION}

The Existing Arch Type, corresponding to the presence of a proper arch, is found in 58.0\% of cases. The Non Arch type was found with a significant frequency, in $42.0 \%$ of cases (Fig. 1).

The most commonly found pattern for the superficial palmar arterial system is the ulnar one, 


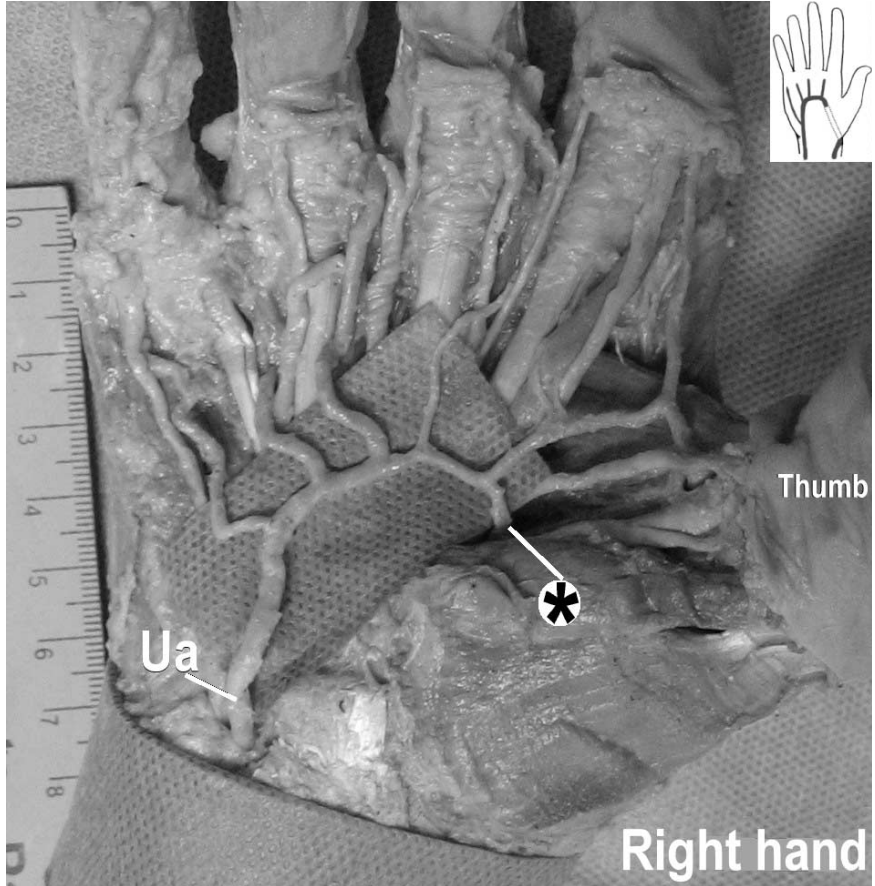

Fig. 5. Ulnar + Radial "proper" pattern. Ua. Ulnar artery; *anastomosis between ulnar and radial arteries.

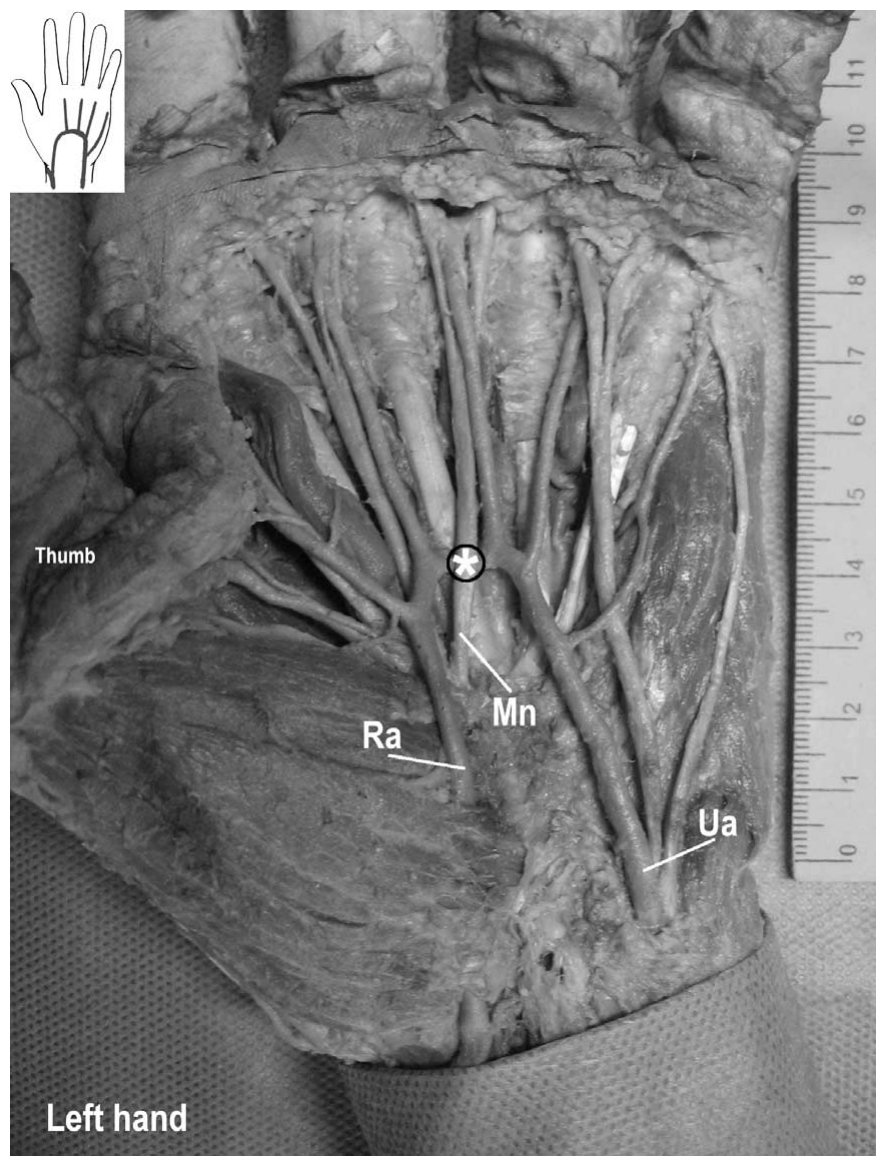

Fig. 6. Classic pattern. RPa, Radiopalmar artery; Ua, Ulnar artery; Mn, Median nerve; * anastomosis between radiopalmar and ulnar arteries. in $44.1 \%$ of cases. This pattern can be defined as the "normal" disposition. Coleman \& Anson found this pattern in $37 \%$ (Table I).

On the other hand, the classic pattern for the superficial palmar arch is not rarely $(22.1 \%)$. This contrasts with other authors' findings (Table I).

Within the Non Arch type, the Dominant Ulnar subtype (the only one in charge of the whole superficial palmar arterial system) is the one that prevails in our investigation $(23.2 \%)$.

Coleman \& Anson established that the arteries of the hand form several diversified patterns which permit classification into well defined categories. The superficial palmar arch is divided into two groups: complete (78.46\%) and incomplete $(21.47 \%)$. They established several types of complete superficial palmar arches,subdivided according to the way in which the contributing arteries join; similarly, there are types of incomplete superficial palmar arches, and are divided at the same way. They considered that there is a compensatory size relationship between the common digital arteries and the volar metacarpal arteries which originate from the deep palmar arch.

Adachi arranged a new classification dividing the superficial palmar arches in three different types according to the tributary vessels. The resulting groups were: Ulnar, Radial-Ulnar and Median-Ulnar type.

In our experience, in the Ulnar-Radial subtype the 1 st dorsal interosseal is always as large as the ulnar and supplies the thumb's and the index's collaterals, establishing a true vascular convergence area, "crossroads" style (Figs. 2 and 3), in the thumb's commissure. This should be taken into account when surgically approaching the area due to the risk of injuring this convergence and damaging the vascular circulation of the thumb.

The Arch formation is also described as the anastomosis of the ulnar and median arteries. This pattern has an important embryological correlate. According to Rodríguez-Niedenführ et al. (1999) the median artery has two patterns: the antebrachial, ending at the level of the forearm $(76 \%)$ and the palmar pattern, wich consists of an artery accompanying the median nerve in the forearm and extending down to the palm while supplying digitals to the fingers (20\%). Other authors, as McCormack et al. (1953) and Fazan et al. (2004), found this disposition 


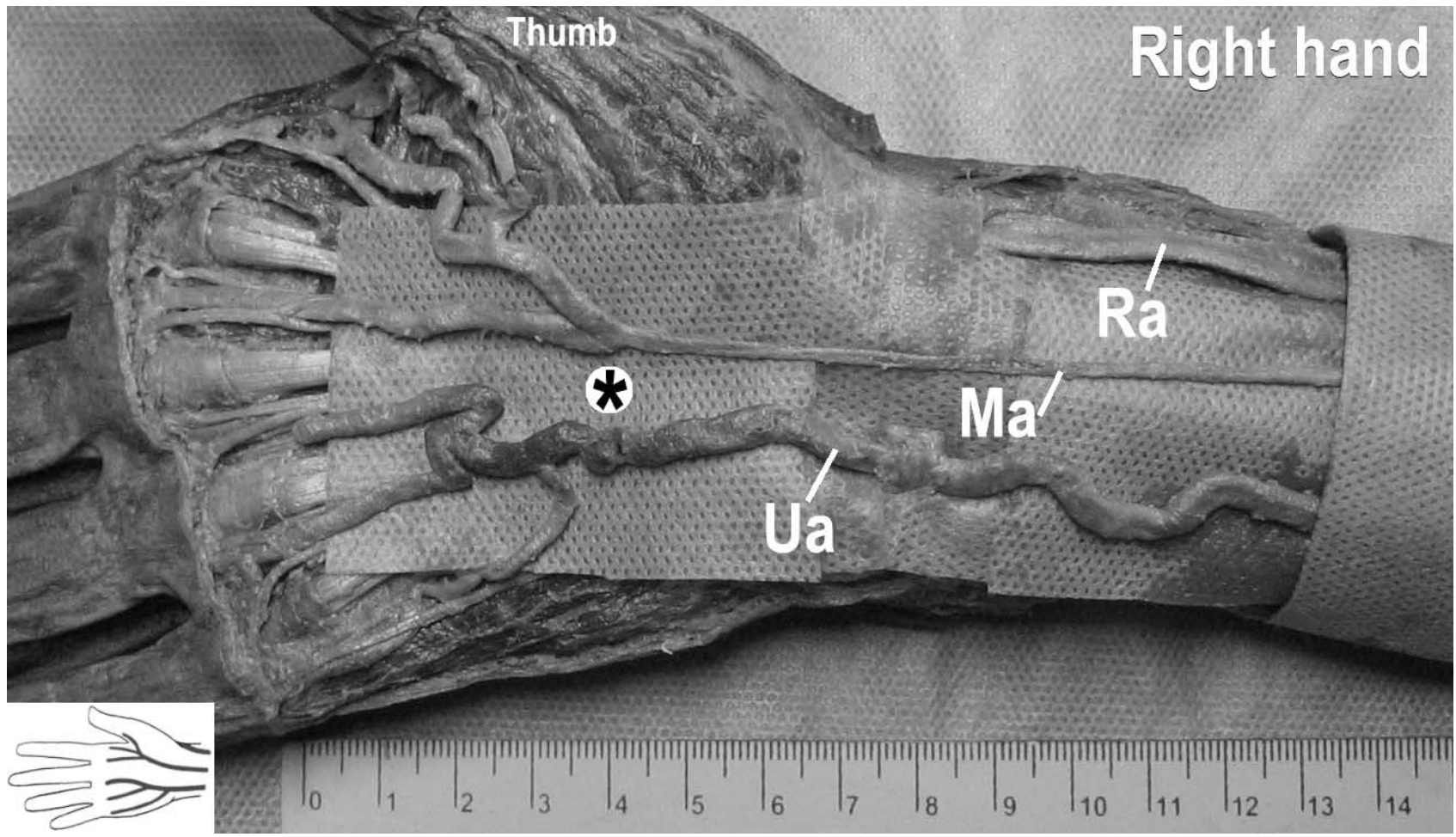

Fig. 7. Ulnar / Median pattern. Ua, Ulnar artery; Ma, Median artery; Ra, radial artery; * absence of anastomosis between ulnar and median arteries.

in a $10 \%$ of the cases. Patnaik et al. (2000) reported a case of persistent median artery with double superficial palmar arch.

According to Rodríguez-Niedenführ et al. (2001a), by stage 21 of the embryo, the radial artery acquires its final differentiated state. The arterial variations affecting the distal course of this artery must be established before stage 21 for it had already acquired its definitive adult morphology (Rodríguez-Niedenführ et al., 2001b).

Some authors describe the superficial palmar arch formation on the basis of the convergence of three arterial vessels: ulnar, radiopalmar and median nerve artery (McCormack et al. 2.4\%, Coleman \& Anson 1.2\%, Olave et al. (1993) 3.3\%). We have not found any arch arrangement with this pattern.

O’Sullivan \& Mitchell (2002), described a variation of the superficial palmar arch related with an absence of the long palmar muscle tendon (palmaris longus). On the contrary, like Fazan et al., we found the long palmar muscle tendon in all cases.

An injury in the ulnar artery or the superficial pal- mar arch may compromise the arterial supply of the fingers, particularly if there is an insufficient anastomosis between the superficial and deep palmar arches (Calenoff, 1972).

Based on our experience, the ulnar artery always takes part in the vascularization of the hand, whether it forms an arch or not. Any variations of the arch depend completely on variations of the radial contribution.

Nevertheless, there is one case report about a congenital absence of a left ulnar artery, which was functionally replaced by an abnormally large interosseus artery (Nunoo-Mensah, 1998).

In order to develop surgical procedures for the hand, it is essential to implement both angiographic studies (Color Doppler) and the Allen test. Even if the arteries participating in the superficial palmar arch are not accurately identified, the implementation of an invasive method in the area can evaluate whether their functionality has been preserved or not (Kamienski \& Barnes, 1976). If there is no collateral flow through the ulnar artery, clamping the radial artery is contraindicated as it can result in gangrene of the fingers in a non arch type. 
OTTONE, N. E.; PRUM, N.; DOMINGUEZ, M.; BLASI, E.; MEDAN, C.; SHINZATO, S.; FINKELSTEIN, D.; BERTONE, V. H. Analysis and clinical importance of superficial arterial palmar irrigation and its variants over 86 cases. Int. J. Morphol., 28(1):157-164, 2010

Table. Classic pattern for the superficial palmar arch. Comparison between works and ours (\%).

\begin{tabular}{|c|c|c|c|c|c|c|c|c|c|c|c|c|}
\hline & assifications & $\begin{array}{l}\text { Present } \\
\text { study }\end{array}$ & Adachi & $\begin{array}{l}\text { Coleman } \\
\text { \& Anson }\end{array}$ & $\begin{array}{c}\text { Brau } \\
\mathrm{n} e t\end{array}$ & $\begin{array}{l}\text { Ikeda } \\
\text { et al. }\end{array}$ & $\begin{array}{l}\text { Jelicic } \\
\text { et al. }\end{array}$ & $\begin{array}{l}\text { Olave } \\
\text { et al. }\end{array}$ & $\begin{array}{l}\text { Gellma } \\
\mathrm{n} \text { et al. }\end{array}$ & $\begin{array}{l}\text { Moraes } \\
\text { et al. }\end{array}$ & $\begin{array}{c}\text { Guzman } \\
\text { Lopez }\end{array}$ & $\begin{array}{l}\text { Bilge } \\
\text { et al. }\end{array}$ \\
\hline Adachi's & Ulnar Type & 58.0 & 59.0 & 16,64 & 88.0 & 25.5 & 13.0 & 35 & 42.2 & 23,34 & 75.0 & 48.0 \\
\hline & Radial UlnarType & 37.3 & 32.0 & 73,46 & 12.0 & 73.6 & 85.0 & 51.7 & 42.1 & 63,33 & 18,7 & 48.0 \\
\hline & Median Ulnar Type & 4.7 & 9.0 & 9,90 & - & 0.9 & 2.0 & 13.3 & 15.5 & 13,33 & 3,6 & 4.0 \\
\hline Our Work & Arch Type & 58.0 & - & 78.46 & 12.0 & 96.4 & 87. & 66.70 & 84.4 & 60.0 & - & 86.0 \\
\hline & Ulnar- Radiopalmar subtype & 43.0 & - & 37.0 & - & - & - & - & - & - & - & - \\
\hline & Ulnar pattern & 20.9 & 59.0 & 37.0 & - & 33.2 & - & - & - & - & 75.0 & 34.0 \\
\hline & Classic pattern & 22.1 & 32.0 & 34.5 & 8.0 & 21.3 & 55.0 & 30.0 & 35.5 & 36.67 & - & - \\
\hline & Ulnar-Radial subtype & 15.0 & - & 2.0 & - & - & - & - & - & - & - & - \\
\hline & $\begin{array}{l}\text { Ulnar + Radial "proper" } \\
\text { pattern }\end{array}$ & 7.0 & - & - & 4.0 & - & - & - & - & - & - & - \\
\hline & Ulnar + 1st DI pattern & 8.0 & - & - & - & - & 20.0 & - & - & - & - & 28.0 \\
\hline & Non Arch Type & 42.0 & - & 21.47 & 88.0 & 3.6 & 13.0 & - & 15.5 & 40.0 & - & 14.0 \\
\hline & Dominant Ulnarsubtype & 29.0 & - & - & - & - & - & - & - & 23.34 & - & 14.0 \\
\hline & Ulnar pattern & 23.2 & - & 13.4 & 60.0 & 25.5 & - & 5.0 & - & - & - & - \\
\hline & $\begin{array}{l}\text { Ulnar / Radiopalmar thenar } \\
\text { pattern }\end{array}$ & 5.8 & - & - & 28.0 & - & - & 15.0 & 42.2 & - & - & - \\
\hline & Codominant Subtype & 13.0 & - & - & - & - & - & - & - & - & - & - \\
\hline & Ulnar/ Radiopalmar pattern & 8.3 & - & 3.2 & - & 3.6 & - & - & - & - & - & 8.0 \\
\hline & Ulnar Medianpattern & 4.7 & 9.0 & 3.8 & - & - & - & 6.7 & - & 3.33 & 3.6 & 4.0 \\
\hline
\end{tabular}

In conclusion, the superficial palmar arch is the main vascular structure of the palm (Gajisin \& Zbrodowski, 1993). Ulnar artery prevails as far as irrigation of the hand, either forming an arch or not. Variations occur mainly in the radial part of the arch (Jelicic et al., 1988). The anatomic knowledge of the variability in the arch formation becomes important in the application of surgical techniques that can help treating pathologies of the hand.

\section{ACKNOWLEDGEMENTS}

We are grateful to Prof. Dr. Mariano del Sol for his unselfish and invaluable contribution to this paper. We are also grateful to Virginia Garrote, Juliana Baraldo and all the staff of Buenos Aires Italian Hospital library for their help to search for several of the articles used in this paper.

OTTONE, N. E.; PRUM, N.; DOMINGUEZ, M.; BLASI, E.; MEDAN, C.; SHINZATO, S.; FINKELSTEIN, D.; BERTONE, V. H. Análisis e importancia clínica de la irrigación arterial palmar superficial y sus variaciones sobre 86 casos. Int. J. Morphol., 28(1):157$164,2010$.

RESUMEN: La descripción clásica del arco palmar superficial de la mano se basa en la anastomosis entre las arterias ulnar y radiopalmar, rama de la arteria radial. Igualmente, la formacion del arco es altamente variable desde el punto de vista del tamaño de las arterias que lo conforman y a la existencia de ramas provenientes de otras arterias y que se suman a las anteriores como tributarias del arco. El objetivo de este trabajo fue clasificar estas posibles variaciones, para definir la formacion del arco, las razones de su composicion variable y la importancia de sus aplicaciones clínicas y quirúrgicas. Fueron disecadas 86 manos, formolizadas al 40\%. Existía prevalencia de la arteria ulnar respecto a su tamaño, con o sin la formación de arco. El conocimiento anatómico de la variabilidad de la formación del arco palmar superficial es de fundamental importancia en la aplicación de técnicas quirúrgicas que pueden ayudar en el tratamiento de diversas patologías de la mano.

PALABRAS CLAVE: Arco palmar superficial; Anatomía; Variaciones anatómicas; Mano. 


\section{REFERENCES}

Adachi, B. Das arteriensystem der Japaner. Kyoto, Marusen Co., 1928.

Bouchet, A. \& Cuilleret, J. Anatomía: descriptiva, topográfica y funcional. $1^{\mathrm{a}} \mathrm{Ed}$. Buenos Aires, Panamericana, 1997.

Calenoff, L. Angiography of the hand: guidelines for interpretation. Radiology, 102(2):331-5, 1972.

Casiraghi, J. C.; Anapios, R. \& Cúneo, J. L. Anatomía del cuerpo humano: funcional y quirúrgica. Regiones del abdomen y de la pelvis. Buenos Aires, El Ateneo, 1969.

Coleman, S. S. \& Anson, B. J. Arterial patterns in the hand based upon a study of 650 specimens. Surg. Gynecol. Obstet., 113:409-24, 1961.

Fazan, V. P.; Borges, C. T.; Da Silva, J. H.; Caetano, A. G. \& Filho, O. A. Superficial palmar arch: an arterial diameter study. J. Anat., 204(4):307-11, 2004.

Gajisin, S. \& Zbrodowski, A. Local vascular contribution of the superficial palmar arch. Acta Anat. (Basel), 147(4):248-51, 1993.

Goss, C. M. Gray Anatomía. Salvat, Barcelona, 1976.

Jelicic, N.; Gajisin, S. \& Zbrodowski, A. Arcus palmaris superficialis. Acta Anat. (Basel), 132(3):187-90, 1988.

Kamienski, R. W. \& Barnes, R. W. Critique of the Allen test for continuity of the palmar arch assessed by Doppler ultrasound. Surg. Gynecol. Obstet., 142(6):861-4, 1976.

Kaplan, E. B. Anatomía Funcional y Quirúrgica de la Mano. $1^{\text {a }}$ Ed. Buenos Aires, Editorial Artécnica, 1961.

Little, J.; Zylstra, P.; West, J. \& May, J. Circulatory patterns in the normal hand. Br. J. Surg., 60(8):652-5, 1973.

McCormack, L.; Cauldwell, E. \& Anson, B. Brachial and antebrachial arterial patterns. A study of 750 extremities. Surg. Gynecol. Obstet., 96(1):43-54, 1953.

Nunoo-Mensah, J. An unexpected complication after harvesting of the radial artery for coronary artery bypass grafting. Ann. Thorac. Surg., 66(3):929-31, 1998.
Olave, E.; Prates, J. C.; Mandiola, E.; del Sol, M. \& Gabrielli, C. Formaciones arteriales superficiales de la palma de la mano. Rev. Chil. Anat., 11(1):35-40, 1993.

O'Sullivan, E. \& Mitchell, B. S. Association of the absence of palmaris longus tendon with an anomalous superficial palmar arch in the human hand. J. Anat., 201(5):405-8, 2002.

Patnaik, V. V. G.; Kalsey, G. \& Singla, R. K. Superficial palmar arch duplication - A case report. Anat. Soc. India, 49(1):63-6, 2000.

Rodríguez-Niedenführ, M.; Burton, G. J.; Deu, J. \& Sañudo, J. R. Development of the arterial pattern in the upper limb of staged human embryos: normal development and anatomic variations. J. Anat., 199(4):407-17, 2001a.

Rodríguez-Niedenführ, M.; Sañudo, J. R.; Vázquez, T.; Nearn, L.; Logan, B. \& Parkin, I. Median artery revisited. J. Anat., 195(1):57-63, 1999.

Rodríguez-Niedenführ, M.; Vázquez, T.; Nearn, L.; Ferreira, B.; Parkin, I. \& Sañudo, J. R. Variations of the arterial pattern in the upper limb revisited: a morphological and statistical study, with a review of the literature. J. Anat., 199:547-66, 2001b

Testut, L. \& Latarjet, A. Tratado de anatomía humana. $9^{\mathrm{a}}$ Ed. Barcelona, Salvat editores, 1954.

Correspondence to:

Nicolás E. Ottone

School of Medicine

Universidad de Buenos Aires

Melincué 5308

Zip Code: 1408

Ciudad Autónoma de Buenos Aires

ARGENTINA

Telephone: 00540111564627355

Email: nicolasottone@gmail.com

Received: 27-09-2009

Accepted: 14-12-2009 